\title{
How we have motivated students in sciences
}

\author{
Uukkivi, Anne ${ }^{a}$ and Labanova, Oksana ${ }^{b}$ \\ ${ }^{\mathrm{a}, \mathrm{b}}$ Centre for Sciences, TTK University of Applied Sciences, Estonia
}

\begin{abstract}
For improving academic performance teachers must search for possibilities to increase students' motivation. Teachers must understand that what motivates teachers may not motivate students (Wiesman 2012). The aim of the article is to present what has helped to motivate students in learning sciences. The article is based on the results of qualitative feedback questionnaires.
\end{abstract}

Although the studies took place mostly in face-to-face classes, students liked to have all the materials in e-learning environments. The most preferred were tutorial videos made with software applications that have the ability to turn a digital device into a virtual board using screen zoom and annotation tools in parallel. These encouraged learners to solve their tasks independently. Online calculators helped to solve more difficult exercises as they offer stepby-step solutions. The choice of bonus tests which were made using interactive videos also received a very positive feedback. Full-time students considered game-based learning platforms to be the most effective revision technique. Using some learners as tutors in teaching was also highly appreciated.

Most of the above-mentioned methods support self-studying, therefore, learners need effective learning tools and materials, particularly for independent learning.

Keywords: Students' motivation; teaching experience; educational technology; teaching sciences; blended learning; higher education. 


\section{Introduction}

In a competitive environment, the number of graduates is for the universities a very important factor (Breen \& Lindsay 1999; Winn 2002; Lukkarinen \& Koivukangas 2017). Achieving a higher number of graduates poses a challenge for the teachers. Students are unmotivated and without an interest to learn (Hidi \& Harackiewicz 2000), they have different subject knowledge and learning skills (Winn 2002), distance students and also many daytime students need to work to cope (Uukkivi \& Labanova 2017). These are just some challenges the teachers face.

However, students vary in beliefs, values and attitudes toward learning (Breen \& Lindsay 1999). There are different factors that affect their willingness to learn. According to Ryan \& Deci's (2000) self-determination theory, if external events promote the feeling of support and security, intrinsic motivation will increase. For improving students' academic performance teachers must search for possibilities to increase students' motivation. At the same time teachers must realize that students and lecturers may not be motivated

in the same way (Wiesman 2012). The aim of the article is to present what has helped us in motivating students in learning sciences.

\section{Methods}

This paper presents the results from TTK University of Applied Sciences in the subjects "Mathematics I" and "Data and text processing" in year 2017.

"Data and text processing" represents 3 ECTS-credit points. The objective of the course is to create conditions to successfully use MS Office in studies and workplaces. This is a blended learning course in Moodle environment. The subject is based on project learning. The course consists mainly of practical work in classroom and teamwork and independent learning outside the classroom. Independently the students need to get acquainted with study materials, complete half-finished exercises and do repetitive exercises as teamwork.

"Mathematics I" represents 3 ECTS credits. The programme of this course contains the main subjects of the gymnasium mathematics programme. This course provides sound knowledge of mathematics and explains how to use mathematics as a tool in engineering. In this course students also develop their logical and mathematical thinking ability. Students who have completed this course are well prepared for more in-depth studies in the subsequent mathematical courses (Mathematics II and III). Learning and teaching are supported by a Moodle course with different types of materials, tests and videos. The methods used are lectures, seminars, demonstrations, classroom discussions, flipped classroom. 
The article is presenting the results that emerged from the qualitative analysis of openended questions collected through the feedback questionnaire of both subjects. The feedback questionnaire of the subject "Data and text processing" consisted of 10 questions and "Mathematics I" from 9 questions. Among the different questions the students of both subjects had to answer to three common question: express their opinion on the teaching format, engagement with study materials, and explain what they liked most in the learning process and assessment. Feedback was requested in the end of the semester in Moodle environment. The feedback was not anonymous. Overall 149 responses were received from all the 311 students. The respondents were both daytime and distance students who study different specialties: Transport and Logistics, Automotive Engineering, Electrical Engineering, Production and Production Management, Building Construction, Road Construction, Facilities Management and Construction Geodesy.

We coded and categorised the answers thematically according to Flick (2011). First we familiarised ourselves with the data, then started to create initial codes, sorted the different codes into potential themes, refined those themes and wrote a detailed analysis for each theme. The five most commonly coded themes have emerged. Themes are as follows: 1 . The importance of the course in virtual learning environment (VLE) 2. Learning materials 3. Bonus tests 4. Revision with game-based platforms 5. Students as tutors.

\section{Findings}

\subsection{The importance of course in $V L E$}

A half of the students emphasised the importance and availability of our supportive teaching and learning e-course and its structure.

Student 1: There was clear guidance on the e-course to explain what we need to do and how. If I had any problems, I had a change to post my question into online forum and answers came quite quickly.

Student 2: In spite of our fast pace in classroom, distance learners have a very good teaching system. Online materials are meaningful and helpful. This is a very supportive ecourse.

In case of face-to-face learning, the location limits attendance to a group of learners who have the ability to participate in the area, and as concerns case the time, it limits the crowd to those who can attend at a specific time. So, we are convinced that absolutely all the materials, learning tasks and guidance should be available in VLE. We used Moodle environment. The feedback shows that such an approach is highly appreciated by our students, especially by distance learners. This understanding of flexibility and the ability to 
remotely access a classroom in the student's own time facilitates and motivates students to learn independently and to achieve learning outcomes.

\subsection{Learning materials}

Students appreciated all types of learning materials (.pdf files, formula sheets, tutorial and instructional videos, text-based guidance with pictures) that were presented in the Moodle courses. A half of the students rated our tutorial videos the highest.

Student 3: Mathematics I" course was the best of TTK UAS in this semester thanks to videos.

Student 4: I particularly liked the tutorial videos which were fundamental in helping to understand the topics.

Tutorial videos are a key component in our Moodle courses and it became an undivided part of our learning process. While there is a lot of existing content on the Internet, there are only few of them in mathematics in the Estonian language. All our videos are in the Estonian language and we can convey the material through auditory and visual channels, creating a multisensory learning environment. Our tutorials do not attempt to achieve too much in a short period of time because they would then become muddled, bloated and difficult to follow. To avoid this, we write plans for our tutorials that will not result in more than 4-9 minutes worth of video.

We use videos mainly in two ways: to support or enhance the understanding of the course content, or as the primary mode of content acquisition. So there are different types of tutorial videos in our courses: mini-lectures, tutorial (problem solving walkthrough), howto or step-by-step videos, interactive videos, individual videos. For creating videos we use such tools as Lensoo Create, Screencast-O-Matic, Zoom, Power Point, H5P and ZoomIt.

Lensoo Create is a virtual whiteboard with voice recording and instructors draw and write freehand digitally on a digital tablet. Lensoo Create provides an opportunity to answer promptly students' individual questions (finding mistakes, giving further instructions, etc.) and it is extremely useful when we want to illustrate problems in sciences. With the help of Lensoo Create we also create mini-lectures videos to implement the flipped classroom model.

Screencasts are another option that we use to make videos. We found it very comfortable for making "how-to" tutorials. In those "how-to" short videos we give instructions to students on how to use special software (MS Excel, MS Word). Also we need screencasts to help our students to understand how some free online calculators such as Symbolab, Desmos, and Wolframalpha work. For example Symbolab provides automated step by step 
solutions to algebraic, trigonometric and calculus topics. Our students find that this corresponds to the $21^{\text {st }}$ century working life requirements and also stimulates them to solve problems independently, knowing that they can check their answers and often also the solution steps online in a minute.

Today's internet viewers have very high expectations to their web content, so we diversify videos with annotations, arrows, circles, and other graphics and texts, it is probably the best way to demonstrate during recordings what we are trying to teach. In this context ZoomIt helps us a lot. ZoomIt is a zoom and annotation tool for presentations, it resizes the capture window dynamically during the recording without pausing or external editing later. Such "keep moving" on the screen definitely helps to focus on the main aspects.

Our students also pointed out interactive videos. An interactive video is a type of interactive content that creates engagement by layering other types of interactions (multiple choiceand fill-in-the-blank questions, pop-up text and other) on top of an existing video. For this purpose we use a free content collaboration framework called H5P and EdPuzzle. Students can skip to specified sections of the video on demand. Such interactive videos motivate students to watch them, as they will receive instant feedback, it is like turning a monologue into a dialogue, moving from a passive to an active viewing experience.

By using tutorial videos we create the opportunity for students to master tough concepts by watching "movements" at their own pace.

\subsection{Bonus tests}

"Mathematics I" course consists of several tests: classroom tests, online grade tests, selftests, bonus tests. The students liked bonus tests the most. Nearly half of the students reported that the bonus tests system motivated them to complete those tests.

Student 5: Bonus tests are a good motivator for raising your grade points!

Student 6: Certainly, great help were bonus tests which helped to improve the ratings and thanks to these tests the knowledge improved.

The bonus test system was as follows. For each learning outcome, a short bonus test was possible. The motivation for completing those tests was that extra points could be obtained. On the other hand, it provided a good overview to both the student and the teacher about the extent the learning outcomes were achieved. A large majority of students tried to pass all the tests. Under each topic several self-tests were also available on the Moodle course. Students reported that because of the flexibility of materials they were engaged and motivated to work independently, it allowed them to schedule their work in a better way and it also helped to self-manage their studies. 


\subsection{Revision with game-based platforms}

Over a half of the daytime students reported on their willingness to answer to online tests made by game-based platforms like Kahoot. When using Kahoot one can add videos, images and diagrams in addition to text questions. Players need to answer the questions on their own devices like smart phones, laptops or tablets, while games are displayed on a shared screen.

Student 7: At the beginning of every lesson there should be a Kahoot quiz to remind us of what we learned last week.

Student 8: More Kahoots!

During the teaching process we use game-based platforms for getting feedback about students' knowledge, understanding and remembering. Such platforms help us to get to know the students' previous knowledge and understanding about new issues. We use gamebased platforms when dealing with the most important mistakes made in exercises, the most important rules and exceptions. Tests made by game-based platforms activate the students and engage them highly. Students like to use nicknames instead of their real names, but they always agree to share their names with the teacher.

When creating the tests we use multiple choice questions where one of those answers is a joke answer. This helps to reduce student tension. We use also incomplete answers to make answering not so easy. It is important to use short questions and answers to make it easier for the students easier to grasp the topic. Unfortunately such platforms do not support mathematical symbols besides power. That is the reason why we use mathematical expressions in picture format.

The only weakness such tests have is related to the quickness of students' answers. Some students tend to answer too quickly, so they do not read all the given answers. This is the reason why we use some exercises after Kahoot to repeat the most important rules.

\subsection{Students as tutors}

Students as tutors are used just in the subject "Data and text processing". About 1/3 of the students liked that some of the students act as tutors.

Student 9: It helped me a lot because if teacher explained the topic to someone else, then it was easier for me to ask the tutor for more clarifications. As well as when having problems with independent work I could instantly write to the course mate in a tutor role.

Student 10: The tutor supported us a lot. It changed our communication for the better and the tutor helped and explained well. 
In the beginning of the school year I give the students an individual exercise to be solved in the classroom. I then ask the quickest and the best ones to stay as tutors. Most of those students agree but some are not so confident or do not want to learn that way and say no.

The tutors need to solve classroom tasks independently before the class does. They send their exercises by e-mail to the teacher and after that the tutor and the teacher discuss the difficulties in the learning materials, exercise guidelines or exercise. After that the tutor will assist the teacher during the class and help other students outside the classes as well when other students are ending half-finished exercises.

The tutors reported that their motivation increased as an alternative way to pass was available, learning was more thorough, flexible, new teaching skills were acquired and above all - there was a good feeling about the possibility to help others.

Student 11: It helped me as well because I had the possibility to revise what we had to learn.

Student 12: It was good that I could help my classmates. I learned how to coach and help others make a great feeling.

The tutors also improved their time management skills because of the strict deadlines and motivated other students due to the positive example. Their role as tutors were wider.

\section{Conclusion}

The results of feedback questionnaires demonstrated how the used materials and methods supported and motivated students to pass technical subjects. Such approach to the course "construction" kept the students active during the entire course and motivated their activities. Those students who used course materials got better results than the usual average grades received in these courses. Also the number of repeats has decreased significantly.

Using supporting face-to-face courses by creating e-course as well, inspiring learning materials, grading system, and game-based platforms has resulted in a win-win situation, as both students and teachers achieved their goals. Students are happier when they have a better command of the whole process and higher marks, while having a better knowledge of the topics included. The factors extracted in this research are similar to the studies of Middleton and Spanias (1999), Erwin (2003), Deshpande \& Chukhlomin (2017 and Huang (2017), where they found out the way of teaching and instructional design quality have great influence on students' motivation.

The above-mentioned materials and methodological techniques supported self-studying, therefore, it allowed them to schedule their work in a better way, also helped to self-manage 
their studies. Learners need effective learning tools and materials, particularly for supporting independent learning. ICT tools have a great value to support students' learning.

Further work is needed to follow up this study in order to elaborate the results to foster deep learning among university students.

\section{References}

Breen, R., \& Lindsay, R. (1999). Academic Research and Student Motivation. Studies in Higher Education, 24(I), 75-93.

Deshpande, A., \& Chukhlomin, V. (2017). What Makes a Good MOOC: A Field Study of Factors Impacting Student Motivation to Learn. American Journal of Distance Education, 31(4), 275-293.

Erwin, J. (2003). Giving students what they need. Educational Leadership, 61, 19-23.

Flick, U. (2011). An Introduction to Qualitative Research. Los Angeles \& London: Sage.

Hidi, S., \& Harackiewicz, J. M. (2000). Motivating the academically unmotivated: A critical issue for the 21st century. Review of Educational Research, 70, 151-179.

Huang, D.-F. (2017). Outcome assessment of the online English learning and management system: A project on educational technology application to English learning in Taiwanese polytechnic higher education. In HEAd'17. 3rd International Conference on Higher Education Advances (pp. 1176-1184). Valencia, Spain: Universitat Politecnica de València. http://dx.doi.org/10.4995/HEAD17.2017.6713.

Lukkarinen, A., \& Koivukangas, P. (2017). Getting in and getting out: Predicting the likelihood of graduation of master's program students. In HEAd'17. 3rd International Conference on Higher Education Advances (pp. 1176-1184). Valencia, Spain: Universitat Politecnica de València. http://dx.doi.org/10.4995/HEAD17.2017.6713.

Middleton, J.A, \& Spanias, P.A. (1999). Motivation for achievement in mathematics: Findings,generalizations, and criticisms of the research. Mathematics Eduction Research Journal, 30(1), 65-88.

Ryan, R. M., \& Deci, E. L. (2000). Self-determination theory and the facilitation of intrinsic motivation, social development, and well-being. American Psychologist, 55(1), 68-78.

Uukkivi, A., \& Labanova, O. (2017). E-learning materials, methods and tools to activate students. In New learning scenarios in digitalized world: international workshop (pp. 31-39). Bucharest, Romania: Conspress.

Wiesman, J. (2012). Student Motivation and the Alignment of Teacher Beliefs. The Clearing House: A Journal of Educational Strategies, Issues and Ideas, 85(3), 102-108.

Winn, S. (2002). Student Motivation: a socio-economic perspective. Studies in Higher Education, 27(4), 445-457. 